\title{
The bioactivity of agarose-PEGDA interpenetrating network hydrogels with covalently immobilized RGD peptides and physically entrapped aggrecan
}

\author{
Ganesh C. Ingavle, Ph.D., Stevin H. Gehrke, Ph.D., and Michael S. Detamore, Ph.D. \\ Department of Chemical and Petroleum Engineering, University of Kansas, Lawrence, KS 66045
}

\section{Abstract}

\begin{abstract}
Our previous reports of interpenetrating networks (IPNs) have demonstrated drastic improvements in mechanical performance relative to individual constituent networks while maintaining viability of encapsulated cells. The current study investigated whether covalent linkage of RGD to the poly(ethylene glycol) diacrylate (PEGDA) network could improve upon cell viability and performance of agarose-PEGDA IPNs compared to unmodified IPNs (control) and to IPNs with different concentrations of physically entrapped aggrecan, providing a point of comparison to previous work. The inclusion of RGD or aggrecan generally did not adversely affect mechanical performance, and significantly improved chondrocyte viability and performance. Although both 4 and $100 \mu \mathrm{g} / \mathrm{mL}$ of aggrecan improved cell viability, only $100 \mu \mathrm{g} / \mathrm{mL}$ aggrecan was clearly beneficial to improving biosynthesis, whereas $100 \mu \mathrm{g} / \mathrm{mL}$ of RGD was beneficial to both chondrocyte viability and biosynthesis. Interestingly, clustering of cells within the IPNs with RGD and the higher aggrecan concentration were observed, likely indicating cell migration and/or preferred regional proliferation. This clustering resulted in a clearly visible enhancement of matrix production compared to the other IPNs. With this cell migration, we also observed significant cell proliferation and matrix synthesis beyond the periphery of the IPN, which could have important implications in facilitating integration with surrounding cartilage in vivo. With RGD and aggrecan (at its higher concentration) providing substantial and comparable improvements in cell performance, RGD would be the recommended bioactive signal for this particular IPN formulation and cell source given the significant cost savings and potentially more straightforward regulatory pathway in commercialization.
\end{abstract}

\section{Introduction}

Fabricating mechanically strong three-dimensional (3D) matrices that support cell growth and tissue formation is a prerequisite for many cell culture and tissue engineering applications [1, 2]. Hydrogels are excellent scaffolding materials for repairing and regenerating a variety of tissues because they can provide a highly swollen 3D environment

\footnotetext{
(C) 2014 Elsevier Ltd. All rights reserved

*Michael S. Detamore, Ph. D. (Corresponding Author) University of Kansas, Department of Chemical and Petroleum Engineering Learned Hall, Room 4132, 1530 W. 15th St., Lawrence, KS 66045-7609 Phone: (785) 864-4943 Fax: (785) 864-4967 detamore@ku.edu. Contact information for other authors: Ganesh C. Ingavle, Ph.D. Phone: (785) 864-4965 Fax: (785) 864-4967 ganesh@ku.edu Stevin H. Gehrke, Ph.D. Phone: (785) 864-4956 Fax: (785) 864-4967 shgehrke@ku.edu Mailing address for other authors: University of Kansas, Department of Chemical and Petroleum Engineering Learned Hall, Room 4132, 1530 W. $15^{\text {th }}$ St., Lawrence, KS 66045-7609.

Publisher's Disclaimer: This is a PDF file of an unedited manuscript that has been accepted for publication. As a service to our customers we are providing this early version of the manuscript. The manuscript will undergo copyediting, typesetting, and review of the resulting proof before it is published in its final citable form. Please note that during the production process errors may be discovered which could affect the content, and all legal disclaimers that apply to the journal pertain.
} 
similar to soft tissues [3-9] and allow diffusion of nutrients and cellular waste through the elastic network. However, most synthetic hydrogels typically exhibit minimal biological activity $[3,4]$ with a lack of desired mechanical integrity and may not provide an ideal environment for encapsulated cells. Mimicking the mechanical aspects of natural tissues can be used to enhance the functionality of engineered tissues and the development of hydrogels that are stronger mechanically may be beneficial for various biological and biomedical applications [10, 11].

By generating composite hydrogels, it may be possible to reproduce the properties of a natural extracellular matrix (ECM). One approach to creating composite materials is the fabrication of an interpenetrating network (IPN) of polymers. An IPN consists of a polymer network containing molecularly entangled chains of a second polymer [12]. It has been demonstrated that synthetic and non-biological IPN hydrogels can achieve an increase in strength, failure stress, and stiffness while maintaining elasticity [13-15]. The research team of JP Gong and Y. Osada at Hokkaido University in Japan reported the synthesis of interpenetrating networks of various combinations of biological and synthetic polymers with dramatically improved mechanical properties [16-25]. Regarding biomedical applications, they recognized that the properties they measured with these IPNs compared favorably with biomaterials such as cartilage. Recently, a new hydrogel consisting of an IPN of alginate and polyacrylamide (PAAM) was reported that displayed remarkable mechanical properties [26]. They explored the maintenance of mechanical properties of these extremely tough IPN hydrogels as a surface for mouse mesenchymal stem cell culture and as a material for in vivo acellular implantation [27]. These cells exposed to the IPN gel-conditioned media maintained high viability. Implantation of these IPN hydrogels into subcutaneous tissue of rats for 8 weeks led to mild fibrotic encapsulation and minimal inflammatory response, suggesting this as a possible biomaterial strategy in tissue engineering application. However, such IPNs are generally not applicable for cell encapsulation due to toxic materials, toxic photoinitiators, shorter photopolymerization wavelengths, and/or lengthy photopolymerization times.

Incorporation of various bioactive signals into biomaterials has enhanced the adhesion of cells $[28,29]$ and may promote an enhanced biomimetic environment for encapsulated cells suspended in 3-dimensional hydrogels. Biological molecules can provide cues to stimulate cells to proliferate, migrate, differentiate, and produce ECM. To the best of our knowledge, aggrecan, a key structural component of cartilage [30], has not been used in its purified form by others as a bioactive signal in scaffolds for cartilage tissue engineering, although its demonstrated ability to promote chondrogenesis in monolayer culture [31, 32], along with its ability to improve chondrocyte performance in IPNs in our previous work [33], together provide a strong rationale for evaluating aggrecan as a signal and/or "raw material" (i.e., building block) in cartilage tissue engineering [34]. The cell-adhesive peptide sequence ArgGly-Asp (RGD) has been shown to promote viability, proliferation, and biosynthesis with various cell types in tissue engineering applications [35-41]. As a result, RGD, which is found in cell-binding domains of extracellular matrix proteins, has been widely used in biomaterials where cell adhesion is desired. With the aim of providing a cellular microenvironment mimicking that found in vivo, recent efforts have been made to incorporate specific peptide sequences into the scaffold architecture, both to encourage biospecific cell adhesion and to induce and control other cellular functions, such as migration, proliferation, ECM synthesis, and tissue remodeling [42].

To facilitate cell adhesion, small peptides derived from extracellular matrix (ECM) proteins have been important targets for the covalent coupling type of bio-specific modification [37, 43-51]. For example, RGD-modified PEG monoacrylate was copolymerized with PEG diacrylate (PEGDA) to create cell-adhesive PEG hydrogels [37, 50, 51]. Different peptide 
sequences have been included successfully in photopolymerizable single network polyethylene glycol (PEG)-based hydrogels [50, 52-55] and in poly(D,L-lactico-glycolic acid) (PLGA) scaffolds [56]. Recently, we introduced the approach of including a "raw material" from cartilage, namely aggrecan or chondroitin sulfate (CS), to serve as a bioactive signal to cells encapsulated in IPN based on agarose -PEGDA hydrogels for cartilage tissue engineering, which led to significantly improved in vitro performance of encapsulated chondrocytes [33, 57].

Given our previous success with aggrecan, and the success of others with RGD in singlenetwork PEGDA gels, our goal was to determine whether the more cost-effective RGD would provide comparable benefits to cell performance, or whether the more expensive aggrecan would provide significantly better results that would better justify its use. We further expanded on our previous work by investigating two different aggrecan concentrations ( 4 and $100 \mu \mathrm{g} / \mathrm{mL}$ ), as opposed to our previous study that examined only a single concentration of $40 \mu \mathrm{g} / \mathrm{mL}$ [33]. This approach of encapsulating cells with bioactive signals is expected to be a valuable tool in investigating the cell-material interactions in a high toughness IPN hydrogel and to design a bio-functionalized material scaffold for cartilage tissue engineering applications.

\section{Materials and Methods}

\subsection{Materials}

High purity PEG diacrylate (DA) (average molecular weight $2000 \mathrm{Da}$ ) was obtained from Sunbio Inc. (Anyang city, South Korea). The photoinitiator, 2-hydroxy-1-[4-(2hydroxyethoxy) phenyl] 2-methyl-1-propanone (Irgacure 2959), was purchased from Ciba Specialty Chemicals Corp. (New York, NY). Acryloyl-PEG-N-hydroxysuccinimide (ACRLPEG-NHS) (3400 Da, Laysan Bio Inc, AL, USA) was used as received. 2-hydroxyethyl agarose (Type VII, cell culture grade), aggrecan from bovine articular cartilage and arginine-glycine-aspartic acid (RGD) ( $297 \%$ purity) were obtained from Sigma-Aldrich (St. Louis, MO) and were used as received.

\subsection{Arg-Gly-Asp (RGD)-modified PEG monoacrylate synthesis and immobilization of RGD on PEG network}

Acrylate-PEG-RGDS was synthesized following previously described methods [37]. Briefly, Arg-Gly-Asp (RGD) was reacted with an equimolar amount of acrylate-PEG-Nhydroxysuccinimide in a sodium bicarbonate buffer $(50 \mathrm{mM}, \mathrm{pH} 8.2)$ for $2 \mathrm{~h}$ at room temperature. The $\mathrm{N}$ terminal $\mathrm{a}$-amine of the RGD peptide was coupled with active $\mathrm{N}$ hydroxysuccinimide ester from acrylate-poly(ethylene glycol)-N-hydroxy succinimide (acrylate-PEG-NHS) to form RGD-modified PEG monoacrylate (acrylate-PEG-RGD) (Fig. 1). The product was lyophilized and stored at $-20^{\circ} \mathrm{C}$ until use. FTIR spectroscopy was performed to assess the RGD coupling with PEGDA in lyophilized solids. A PerkinElmer FTIR One spectrometer (PerkinElmer Life and Analytical Sciences, Waltham, MA) with a universal attenuated total reflectance (UATR) accessory was used to acquire the spectra. The solid sample was placed on a diamond crystal surface and covered with a stainless steel slide, and pressure (100 Torr) was applied to ensure good contact between the protein and the crystal. ${ }^{1} \mathrm{H}$ nuclear magnetic resonance (NMR) was performed on the dried sample to quantify complete RGD conjugation. High-resolution, ${ }^{1} \mathrm{H}$ NMR spectra were taken on a Bruker Advance DRX 500 spectrometer operating at $500 \mathrm{MHz}$. Deuterated water (90\% DI + $10 \% \mathrm{D}_{2} \mathrm{O}$ ) was used as a solvent, and the macromer concentrations were varied between 2.5 and 3 wt. $\%$. 
RGD was then immobilized within the PEGDA network upon copolymerization of acrylatePEG-RGD with the appropriate concentration of PEG-DA monomer by photopolymerization in the presence of the photoinitiator Irgacure $2959(0.1 \% \mathrm{w} / \mathrm{v})$, as illustrated in Figure 2.

\subsection{Chondrocyte isolation and culture}

Articular cartilage samples were dissected aseptically from the ankles of 8-9 month old male Duroc Hogs, which were obtained from a local butcher. Cells were harvested within 36 $\mathrm{h}$ after slaughter following aseptic procedures as described in our previous reports [58, 59]. The articular cartilage samples were diced into approximate $1 \mathrm{~mm}^{3}$ pieces using a scalpel in autoclaved PBS. After rinsing with PBS three times, the cartilage samples were digested in a sterile-filtered solution of $30 \mathrm{~mL}$ of $2 \mathrm{mg} / \mathrm{mL}$ type II collagenase $(305 \mathrm{U} / \mathrm{mg}$; Worthington Biochemical) for $18 \mathrm{~h}$ on an orbital shaker in a humidified $37^{\circ} \mathrm{C}, 5 \% \mathrm{CO}_{2}$ incubator. The digested cartilage solution was filtered through a $100 \mu \mathrm{m}$ filter cell strainer to remove undigested cartilage lumps. The filtrate was then centrifuged at $1500 \mathrm{rpm}$ for $5 \mathrm{~min}$, and then the cell pellet was resuspended in chondrocyte culture medium in a humidified incubator $\left(37^{\circ} \mathrm{C}, 5 \% \mathrm{CO}_{2}\right)$. The culture medium consisted of Dulbecco's modified Eagle's medium (DMEM) with $4.5 \mathrm{~g} / \mathrm{L}$ D-glucose supplemented with $10 \%$ fetal bovine serum (FBS), $1 \%$ nonessential amino acids, $1 \%$ sodium pyruvate, $50 \mu \mathrm{g} / \mathrm{mL}$ ascorbic acid and $0.25 \mathrm{mg} / \mathrm{mL}$ penicillin-streptomycin-fungicide. The DMEM and supplements were obtained from Invitrogen (Grass Islands, NY). The cell number was determined using a hemocytometer. The freshly isolated cells were grown to $90-95 \%$ confluence in T75 flasks and then retrieved by trypsin-ethylenediaminetetraacetic acid (EDTA) digestion. First passage chondrocytes were used in this study, and culture medium was changed every 2 or 3 days.

\subsection{RGD and aggrecan incorporated agarose-PEGDA IPN synthesis and photo- encapsulation}

To study this incorporation effect, three different IPNs were synthesized and examined: (i) agarose-PEGDA IPN with no bioactive signals (IPN); (ii) agarose-PEGDA IPN containing $4 \mu \mathrm{g} / \mathrm{mL}$ aggrecan (IPN-agg 4); (iii) agarose-PEGDA IPN containing $100 \mu \mathrm{g} / \mathrm{mL}$ aggrecan (IPN-agg 100) and (iv) agarose-PEGDA IPN containing $100 \mu \mathrm{g} / \mathrm{mL}$ RGD (IPN-RGD 100).

Chondrocytes were encapsulated in the bioactive IPN hydrogel using our previously published methods [60]. The chondrocytes were detached from T75 flasks using trypsinEDTA and resuspended in PBS at a high concentration, while an agarose solution was prepared by adding $0.3 \mathrm{~g}$ agarose powder (cell culture grade) to $10 \mathrm{~mL}$ PBS and autoclaving for $30 \mathrm{~min}$. The agarose solution temperature was monitored under an aseptic environment until $39^{\circ} \mathrm{C}$ was reached. Cells from the PBS suspension were counted using a hemocytometer. Once the agarose solution temperature reached $39^{\circ} \mathrm{C}$, the chondrocyte suspension was mixed with the liquid agarose solution in a 1:2 ratio for a final concentration of 25 million cells $/ \mathrm{mL}$ in $2 \%$ agarose. The cell suspension was mixed thoroughly with the agarose solution and pipetted into sterilized cylindrical silicone molds measuring $5 \mathrm{~mm}$ in diameter and $1.9 \mathrm{~mm}$ in height. The molds were clamped and cooled at $4^{\circ} \mathrm{C}$ for $9-10 \mathrm{~min}$, and then chondrocyte-encapsulated agarose gel constructs were transferred to non-tissuecultured 24-well plates. Each well was supplied with $1.5 \mathrm{~mL}$ of fresh growth medium, and placed in an incubator overnight. To make a first network of agarose containing aggrecan, PBS containing aggrecan (Sigma-Aldrich, St. Louis, MO) was added to $10 \mathrm{~mL}$ of agarose solution separately at $39^{\circ} \mathrm{C}$ just before the addition of the cell suspension to achieve final aggrecan concentrations of $4 \mu \mathrm{g} / \mathrm{mL}$ and $100 \mu \mathrm{g} / \mathrm{mL}$. Creation of the first network followed the same aseptic procedure as described above. Similarly, ACRL-PEG-RGD $(100 \mu \mathrm{g} / \mathrm{mL}$ in PBS) macromer was entrapped in the agarose first network. To synthesize chondrocyte- 
encapsulated IPNs, agarose constructs containing $100 \mu \mathrm{g} / \mathrm{mL}$ modified ACRL-PEG-RGD and agarose constructs containing a low concentration $(4 \mu \mathrm{g} / \mathrm{mL})$ as well as a high concentration $(100 \mu \mathrm{g} / \mathrm{mL})$ of aggrecan were soaked separately in a sterile-filtered $15 \% \mathrm{w} / \mathrm{v}$ solution of photopolymerizable PEGDA and Irgacure $2959(0.1 \% \mathrm{w} / \mathrm{v})$ photoinitiator for 2.5 $\mathrm{hr}$. Afterward, the equilibrated gels were placed in rectangular silicon molds between optical glass microscope slides, and the surrounding space was filled with excess PEGDA/PBS solution from the soak vials. The gels were exposed to ultraviolet light for 5 minutes on each side using $312 \mathrm{~nm}$ light at $3.0 \mathrm{~mW} / \mathrm{cm}^{2}$ (XL-100; Spectronics Corp.). The acryloyl vinyl double bond from the entrapped monoacrylated-PEG-RGD macromer was subsequently copolymerized with PEGDA monomer that had diffused into the agarose construct and formed a second network of IPN having RGD peptide sequences (IPN-RGD 100), as illustrated in Figure 3. Similarly, agarose-PEGDA IPNs having $4 \mu \mathrm{g} / \mathrm{mL}$ aggrecan (IPN-agg 4) and $100 \mu \mathrm{g} / \mathrm{mL}$ aggrecan (IPN-agg 100) concentration were synthesized using the same procedure as described above, as illustrated in Figure 4. Using a $3 \mathrm{~mm}$ biopsy punch, gel samples were then cut from the center of the polymerized IPN area of each agarosePEGDA: agarose-PEGDA with $100 \mu \mathrm{g} / \mathrm{mL}$ of RGD (IPN-RGD 100), agarose-PEGDA with $4 \mu \mathrm{g} / \mathrm{mL}$ of aggrecan (IPN-agg 4) and agarose-PEGDA with $100 \mu \mathrm{g} / \mathrm{mL}$ of aggrecan (IPNagg 100).

The IPN constructs with encapsulated cells from each group were then cultured for 6 weeks at $37^{\circ} \mathrm{C}$ with $5 \% \mathrm{CO}_{2}$ in $1.5 \mathrm{~mL}$ chondrocyte growth medium [Dulbecco's modified Eagle's medium (DMEM) with $4.5 \mathrm{~g} / \mathrm{L}$ D-glucose supplemented with $10 \%$ fetal bovine serum (FBS), $1 \%$ non-essential amino acids, $1 \%$ sodium pyruvate, $50 \mu \mathrm{g} / \mathrm{mL}$ ascorbic acid, 0.25 $\mathrm{mg} / \mathrm{mL}$ penicillin-streptomycin-fungicide, and $100 \mathrm{ng} / \mathrm{mL}$ human recombinant insulin-like growth factor (IGF-1) (PeproTech Inc., NJ)]. The medium was replaced every 2-3 days.

Acellular agarose-PEGDA IPNs containing $4 \mu \mathrm{g} / \mathrm{mL}$ and $100 \mu \mathrm{g} / \mathrm{mL}$ aggrecan were synthesized non-aseptically but otherwise using the above photopolymerization procedure. Using a $2 \mathrm{~mm}$ biopsy punch, gels ( $2 \mathrm{~mm}$ diameter and $2 \mathrm{~mm}$ height) were then cut from the IPN area and allowed to equilibrate in PBS and deionized (DI) water for at least $24 \mathrm{~h}$ before use.

\subsection{Swelling properties of IPN gels}

Acellular bioactive IPN gels $(n=3)$ were placed in excess DI water for at least $24 \mathrm{~h}$ to remove extractable materials from polymer networks. Equilibrated gel samples were weighed and placed into a desiccation chamber over calcium sulfate. After at least $48 \mathrm{~h}$, the dried gel samples were removed and weighed again. The equilibrium swelling degree, $\mathrm{Q}$, was defined as the ratio of the fully swollen IPN gel mass to that of its dry mass.

\subsection{Mechanical testing}

The compressive modulus of the IPN hydrogels was determined at room temperature on a RSA-III dynamic mechanical analyzer (TA Instruments, New Castle, DE) and tested under unconfined uniaxial compression with a $35 \mathrm{~N}$ load cell $(\mathrm{n}=5)$. The gel diameter was measured with calipers under a stereomicroscope (20X magnification) and the height was measured directly using the RSA-III. All measurements and mechanical testing were performed on IPN gels swollen to equilibrium in PBS, and compression plates were lubricated with mineral oil both to minimize any gel-plate adhesion and to prevent gel drying during testing. Following a tare load of $35 \mathrm{~N}$, hydrogels were then compressed in the direction normal to the circular face of the IPN gel at a rate of $0.0005 \mathrm{~mm} / \mathrm{s}(1.7 \% / \mathrm{min})$ until fracture occurred. The compressive elastic modulus, defined as the slope of the linear region of the stress-strain curve of a material under compression, was calculated from the initial linear portion of the curve $(<20 \%$ strain). Fracture points were identified at the peak stress 
after which a significant $(>10 \%)$ decrease in stress occurred. The shear moduli G were calculated using the neo-Hookean model for ideal elastomers. For this model, a plot of stress versus the strain function $\lambda-1 / \lambda^{2}$ yields a straight line up to a strain $\varepsilon$ of 0.5 or greater, where $\lambda=\mathrm{L} / \mathrm{L}_{0}=1+\varepsilon$ [61]. The moduli were reported as mean values from sets of at least 5 samples.

\subsection{Encapsulated cell morphology by scanning electron microscopy}

IPN samples $(\mathrm{n}=3)$ seeded with cells were fixed in $10 \%$ buffered formalin and dehydrated by using graded ethanol steps using the critical point drying (CPD) method [62]. To examine the morphologies of cells and cell aggregates inside an IPN, samples were cut with a scalpel blade and were sputter-coated with gold for 30 seconds prior to imaging. The morphology of the encapsulated cells within the IPN hydrogels was evaluated by Carl Zeiss Leo 1550 field emission scanning electron microscope (SEM).

\subsection{Live/dead assay}

Cell viability was assessed using the LIVE/DEAD assay for cell viability (Molecular Probes, Carlsbad, CA). At 0, 3, and 6 weeks post-IPN formation, each cylindrical construct $(\mathrm{n}=3)$ was sectioned parallel to its circular face and incubated with LIVE/DEAD reagent $(2 \mathrm{mM}$ calcein AM, $4 \mathrm{mM}$ ethidium homodimer-1) for 25-30 min before being analyzed with fluorescence microscopy using a Yokugawa CSU10 spinning-disk attached to an Olympus IX 81 microscope with $488 \mathrm{~nm}$ excitation/515-540 nm emission and $561 \mathrm{~nm}$ excitation/585 LP emission filters with a charge-coupled device camera (CoolSnap HQ2; Photometrics) controlled by Slidebook software (version 4.2; Intelligent Imaging Innovations, Inc.). Zscans were performed from a resolution depth of 350-500 $\mu \mathrm{m}$ in areas representative of the overall IPN gels. Images were acquired in $2 \times 2$ binning mode. The three-dimensional images were deconvoluted using a constrained iterative algorithm (Slidebook). The percentage of total viable cells was calculated using the SlideBook (version 5.0) Mask Statistic module.

\subsection{Biochemical assays}

Biochemical assays were performed on the RGD immobilized IPN (IPN-RGD 100) as well as the aggrecan-entrapped IPN (IPN-agg 4 and IPN-agg 100) constructs $(n=4)$. At 0,3 , and 6 weeks, four samples were removed aseptically from culture and placed in microcentrifuge tubes. Samples were mechanically crushed and then homogenized with a papain mixture [125 mg/mL papain (from papaya latex), $5 \mathrm{mM} \mathrm{N}$-acetyl cysteine, $5 \mathrm{mM}$ EDTA, and 100 $\mathrm{mM}$ potassium phosphate buffered saline (PBS)] and allowed to digest overnight in a $60^{\circ} \mathrm{C}$ water bath. All reagents were obtained from Sigma. The digested constructs were then stored at $-20^{\circ} \mathrm{C}$. The digested constructs were thawed in a $37^{\circ} \mathrm{C}$ water bath and centrifuged at $10,000 \mathrm{rpm}$ for $10 \mathrm{~min}$ to pellet fragments of polymers before conducting assays. Supernatant was used to determine glycosaminoglycan (GAG), DNA, and hydroxyproline content. DNA content was quantified using the Picogreen assay (Molecular Probes) according to the manufacturer's instructions. Total GAG content was determined using the dimethylmethylene blue (DMMB) (Biocolor, Carrickfergus, UK) spectrophotometric assay, with chondroitin sulfate as the standard [63]. To account for the GAG content present in aggrecan, the GAG content associated with the incorporated aggrecan was measured in samples $(n=4)$ collected from acellular IPN-agg 4 and IPN-agg 100 gels. These values were subtracted from the GAG values of cellular IPN-agg 4 and IPN-agg 100 samples to obtain the GAG contents reported for the experimental groups. As an indicator of collagen content, a hydroxyproline assay was assessed as described in our previous publication [64]. Both GAG and collagen contents were normalized to DNA content. 


\subsection{Histology}

For histological evaluation, formalin (10\%)-preserved sample sections were stained with safranin $\mathrm{O}$ at 0,3 , and 6 weeks $(\mathrm{n}=2)$. Before sectioning, these constructs were soaked in optimal cutting temperature (OCT) medium [Ted Pella Inc., Redding, CA] overnight at $44^{\circ} \mathrm{C}$. Constructs were then placed in a $-20^{\circ} \mathrm{C}$ freezer until further processing. Sections were cut at $-20^{\circ} \mathrm{C}$ using a cryostat (MICROM HM 550) to $8 \mu \mathrm{m}$ thickness, mounted on a microscope slide and allowed to dry for 1 hour at room temperature. Following standard histological procedures, the sections were stained with safranin $\mathrm{O}$, which stains negatively charged GAGs orange.

\subsection{Statistical analysis}

All quantitative data were expressed as mean \pm standard deviations and statistical analyses were performed by single-factor analysis of variance (ANOVA), followed by Tukey's post hoc analysis. Analysis was performed using the SPSS 17.0 statistical software package. The significance level was set as $p<0.05$.

\section{Results}

\subsection{Design and synthesis of tailed linear RGD peptide macromer and characterizations}

RGD peptide was incorporated into a monoacrylated PEG chain by the reaction of $\mathrm{NH}_{2}$ group of RGD with -NHS group of ACRL-PEG-NHS (Fig.1). The incorporated molecule was then characterized by FTIR. Figure 5 shows the FTIR spectra of ACRL-PEGNHS and ACRL-PEG-RGD. The absorbance peak at $1340 \mathrm{~cm}^{-1}$ was attributed to glycine $\left(-\mathrm{CH}_{2} \mathrm{C}=\mathrm{O}\right)$ and the peak at $960 \mathrm{~cm}^{-1}$ to aspartic acid $(\mathrm{COOH})$ of the RGD peptide covalently bonded to the PEGDA. The absorption peak $1640 \mathrm{~cm}^{-1}$ arises from the $-\mathrm{C}=\mathrm{O}$ stretching vibration. Comparing ACRL-PEG-NHS with ACRL-PEG-RGD, ACRL-PEGRGD had a stronger absorption peak at $1640 \mathrm{~cm}^{-1}$. This was due to the widely distributed $\mathrm{C}=\mathrm{O}$ groups in RGD incorporated within PEG. Another difference occurred at $1735 \mathrm{~cm}^{-1}$, where ACRL-PEG-NHS had a stronger absorption band than ACRL-PEG-RGD. This absorption band resulted from the $-(\mathrm{C}=\mathrm{O})$-NHS group. After incorporation, the $-\mathrm{NHS}$ group was replaced by an $-\mathrm{NH}_{2}$ group. There, the absorption peak at $1735 \mathrm{~cm}^{-1}$ decreased after an incorporation reaction, indicating that RGD peptide was successfully incorporated into the PEGDA macromer. The functionalization of acrylated PEG macromer with peptides was also characterized by NMR (Fig. 6). A multiplet of $-\mathrm{CH}_{2}-\mathrm{COOH}$ of aspartic acid at 2.8 ppm, and a triplet of $-\mathrm{CH}_{2}-\mathrm{CH}_{2}-\mathrm{CH}_{2}-\mathrm{NH}-\mathrm{C}(=\mathrm{NH})-\mathrm{NH}_{2}$ of arginine at $3.1 \mathrm{ppm}$ were observed in the NMR spectra. Disappearance of the proton peak of the N-hydroxy succinimidyl ester at $2.9 \mathrm{ppm}$ was observed after the coupling reaction (Fig. 6).

\subsection{Swelling properties}

The swelling degrees of various equilibrium-swollen IPNs are tabulated in Table 1. The acellular equilibrium IPN-aggrecan 100 and the IPN-RGD gels had $2.4(p<0.05)$ and $1.5(p$ $<0.05)$ times higher swelling degrees than IPN gels containing no bioactive signals at week 0 , respectively (Table.1), while swelling degree of IPN aggrecan 4 was not statistically significant from the IPN group at week 0 . No significant differences were observed between the IPN, IPN-aggrecan 4, IPN-aggrecan-100 and IPN-RGD 100 groups at week 6.

\subsection{Mechanical properties}

Our previous studies of agarose/PEG-DA IPNs showed a large improvement (more than 4fold increase) in mechanical performance compared to both single networks, while maintaining unprecedented cell viability [60]. Furthermore, our more recent study demonstrated that further mechanical improvements are possible by increasing the 
concentrations of both networks as well as the molecular weight of PEG-DA without sacrificing cell viability or activity [65]. The network properties of cellular as well as acellular IPN gel were investigated to verify the compression moduli to ensure that the mechanical properties of the bioactive IPN gel were sufficient for cartilage-like tissue. Mechanical property data of all gels are summarized in Table 1. Shear moduli (G) of acellular IPN-agg 100 and IPN-RGD 100 gels were $23 \%$ and $~ 7 \%$ higher that of IPN gels, respectively $(p<0.05, \mathrm{n}=5$ ), while shear modulus in IPN-agg 4 group did not change significantly in comparison with the IPN gels at week 0 (Table 1). However, the shear moduli in the IPN-agg 100 and IPN-RGD 100 gels decreased by $56 \%$ and $45 \%(p<0.05$, n $=5$ ), respectively from week 0 to week 6 , while decreases in shear moduli from week 0 to week 6 in all other IPN gels were not statistically significant (Table 1). The presence of encapsulated chondrocytes did not significantly compromise mechanical properties of IPN gels at week 0 (Table 1), however shear moduli of all of the IPN cellular gels decreased over 6 weeks $(p<0.05)$. Fracture stress and toughness in the IPN-agg 100 and IPN-RGD 100 gels were relatively higher than the IPN containing no bioactive signals at week 0 , although these differences were not statistically significant (Table 1). The low concentration of aggrecan did not change fracture properties significantly compared to agarose-PEGDA IPN gels. Over time, fracture stress values decreased significantly by $30 \%$ and $41 \%(p<0.05, \mathrm{n}$ = 5) from week 0 to week 6 in IPN-agg 100 and IPN-RGD 100 gels, respectively. Similarly, toughness values decreased significantly by $40 \%$ and $51 \%(p<0.05, \mathrm{n}=5)$ from week 0 to week 6 in IPN-agg 100 and IPN-RGD 100 gels, respectively, although differences over 6 weeks were not significant for the other two groups (Table 1).

\subsection{Photo-encapsulation and chondrocyte viability in IPN gels}

Figure 7 clearly shows different cell-matrix behavior and proliferation rates in each cellular system. Macroscopic images of equilibrium-swelled IPNs with no bioactive signals (Fig. 7A) and IPN-agg 4 (Fig. 7B) did not show any difference in cell behaviors at week 6, but it was observed that encapsulated chondrocytes in IPNs with a high concentration of aggrecan (IPN-agg 100) and immobilized RGD (IPN-RGD 100) started aggregating inside the gel at week 1 . These cell aggregates grew with culture time and produced significant ECM by week 6 in IPN-agg 100 (Figs. 7C) and in IPN-RGD 100 (Fig. 7D). Most of the proliferating cell colonies grew so large that they continued migrating and proliferating beyond the boundaries of the IPN-RGD gels (Fig. 7D). Cellular outgrowth beyond the boundary of the gels was clearly visible in the IPN-agg 100 and IPN-RGD 100 gel groups after 3 weeks of culture in IPN hydrogel constructs and with further culturing until week 6 an abundant tissue growth was generated at the gel edge forming a continuous ring like structure around the gel (Figs. 7C and 7D). However, chondrocytes in the IPNs with the lower concentration of aggrecan and with no bioactive signal did not form any appreciable aggregates. The Live/ Dead assay also revealed the formation of cell aggregates inside the gel (Fig. 8). Comparable cell compatibility was observed among all four IPN systems (Figs. 8A-D) at week 0. Decreasing viability was observed for IPN hydrogels containing no added biomolecules (Fig. 8E) as well as for the IPN containing a low concentration of aggrecan (Fig. 8F) after 3 weeks of in vitro culture. Figures $8 \mathrm{G}$ and $8 \mathrm{H}$ demonstrate the aggregation and migration (outgrowth) phenomena of encapsulated live cells in IPN-agg 100 and IPNRGD 100 IPNs, respectively at week 3. In our previous report, we demonstrated that the IPN synthesis method was compatible with the incorporation of chondrocytes, but chondrocytes did not remain viable over time (after 1 week) when cultured in pure IPN (biomolecule free IPN) [60]. Live/Dead cell staining indicated that $64 \%$ encapsulated cells in the pure IPN (Fig. 8I) and 57\% in IPN-agg 4 (Fig. 8J) died, while more than $70 \%$ of cells remained viable (stained fluorescent green with Calcein) over the culture period of 6 weeks in IPN-agg 100 (Fig. 8K) and IPN-RGD 100 gels (Fig. 8L). This decrease in cell viability in the IPN containing no biomolecules may be attributed, in part, to limited diffusion of nutrients in 
these gels due to their low swelling degree. Mask statistics showed that, in the absence of any bioactive signals (pure IPN gels), viability dropped significantly $(p<0.05)$ from $95 \%$ to $48 \%$ and $30 \%$ at 3 and 6 weeks post-encapsulation in culture, respectively, while by immobilizing RGD within the IPN gels (IPN-RGD 100), the viability moved to $73 \%$ and $72 \%$ at 3 and 6 weeks, respectively, and that of IPN-agg 100 moved to $77 \%$ and $70 \%$, respectively at 3 and 6 weeks (Fig. 9). The low concentration of aggrecan did not help in maintaining long-term cell viability of chondrocytes, as the viability dropped to $38 \%$ at 6 weeks, which did not differ significantly from the aforementioned $30 \%$ viability of the pure IPN system with no biomolecules. There were no statistically significant differences in cell viability among groups at week 0 . At week 3 , there were no statistically significant differences in cell viability between IPN-agg 100 and IPN-RGD 100, although IPN-agg 100 cell viability was $60 \%$ higher than the control $(p<0.05)$. At week 6 , the cell viability was not significantly different between the IPN-agg 100 and IPN-RGD 100 groups, although they were both significantly larger than the control, by factors of 2.3 and 2.4, respectively ( $p$ $<0.05)$. There were no statistically significant differences in cell viability between low aggrecan IPN (IPN-agg 4) and control groups at week 3 and 6.

\subsection{Chondrocyte morphology within IPN hydrogels}

SEM images reveal the interaction of cells and the surrounding IPN hydrogel matrix (Figure 10). Strong tendency of formation of cell clusters/aggregates deep within the gel was observed in IPN-agg 100 (Fig. 10C) and IPN-RGD (Fig. 10D) gels. The IPN hydrogel matrix with high concentration of aggrecan and RGD peptide sequence provides a scaffold environment on which cells could stably settle, but from which they also are able to extrude into three dimensions when they divide.

\subsection{Effect of incorporated RGD and aggrecan biomolecules on cell proliferation and extracellular matrix (ECM) synthesis}

The initial cell density (after encapsulation) as well as cell proliferation during culture (within the hydrogels) was analyzed by DNA content measurements (Fig. 11). At week 6, the DNA contents in IPN-agg 100 and IPN-RGD 100 were 3.1 and 1.6 times higher than their values at week 0 , respectively $(p<0.05)$. No significant change was observed in the DNA contents of the IPN group containing no biomolecules and the IPN group with a low concentration of aggrecan between week 0 and week 6 . There were no statistically significant differences in DNA content among groups at week 0 . At week 3 , the DNA content in the IPN-agg 100 group was 34\% higher than in the IPN-RGD 100 group ( $p<$ $0.05)$, which in turn was $39 \%$ higher than in the control $(p<0.05)$. Similarly at week 6 , the DNA content in the IPN-agg 100 group was $21 \%$ higher than in the IPN-RGD 100 group $(p$ $<0.05)$, which in turn was $47 \%$ higher than in the control $(p<0.05)$. No significance difference was observed between the IPN-agg 4 and control groups at week 3 or week 6 . Production and accumulation of major cartilaginous matrix components such as GAGs and collagen were measured (Figs. 12 and 13). We reiterate that the GAG contents of acellular aggrecan gels were measured as baseline values, and that the GAG contents reported here for the aggrecan IPN groups represent that actual measured GAG content minus the baseline acellular GAG content. It was observed that all of the IPN gels accumulated GAGs over 6 weeks (Fig. 12). We observed a time-dependent increase in total glycosaminoglycan (GAG) deposition in IPN-agg 100 and IPN-RGD 100 groups. There were no statistically significant differences in either total or normalized GAG content among groups at week 0 (Fig. 12). At week 3 , the total GAG contents were not significantly different between the IPN-agg 100 and IPN-RGD 100 groups, although they were both larger than the control, by 2.4 and 2 times $(p<0.05)$, while normalized GAG contents in IPN-agg 4 and IPN-RGD 100 were larger than the control by $47 \%$ and $22 \%$, respectively (Fig. 12A). At week 6, the total GAG content in the IPN-agg 100 group was 19\% higher than in the IPN-RGD 100 group, which in 
turn was 2.4 times $(p<0.05)$ larger than in the control. However, the normalized GAG contents were not significantly different between the IPN-agg 100 and IPN-RGD 100 groups, although they were both larger than the control, by $31 \%$ and $27 \%(p<0.05)$, respectively, at week 6 . Normalized GAG content values (to total DNA) increased from week 0 to week 6 for the IPN-agg 100 and IPN-RGD 100 gels by factors of 2.3 and 10.6, respectively $(p<0.05, \mathrm{n}=4$ ), although the control did not demonstrate a significant increase (Fig. 12B). After 6 weeks of culture, chondrocytes in the IPN without biomolecules and the IPN with a low concentration of aggrecan (IPN-agg 4) produced comparable amounts of normalized GAGs (Fig. 12B). Results from the quantitative analysis of collagen (by hydroxyproline assay) are presented in Figure 13. There were no statistically significant differences in either total or normalized hydroxyproline content among groups at week 0 . At week 3 , the total hydroxyproline contents were not significantly different between the IPNagg 100 and IPN-RGD 100 groups, although they were both significantly larger than the control, by 4.4 and 5.9 times, respectively ( $p<0.05$ ), Similarly, normalized hydroxyproline contents in IPN-agg 100 and IPN-RGD 100 groups were significantly larger than the control, by 2.1 and 3.7 times, respectively $(p<0.05)$. The total as well as normalized hydroxyproline contents were not significantly different between the IPN-agg 4 and control IPN groups at week 3. Similar to GAG, both the total (Fig. 13A) and normalized (Fig. 13B) hydroxyproline content increased significantly $(p<0.05, \mathrm{n}=4)$ in all four groups at week 6 in comparison to their hydroxyproline content at week 0 . At week 6 , the total hydroxyproline content in the IPN-agg 100 group was 27\% higher than in the IPN-RGD 100 group $(p<0.05)$, which in turn was 2.3 times larger than in the control $(p<0.05)$. However, the normalized hydroxyproline contents were not significantly different between the IPNagg 100 and IPN-RGD 100 groups, although normalized hydroxyproline content in IPN-agg 4 was $37 \%$ larger than the control $(p<0.05)$. At week 6 , the IPN control, IPN-agg 4, IPNagg 100, and IPN-RGD 100 groups showed 5.2, 5.7, 2.6 and 12.7 fold increases in normalized collagen content, respectively relative to their values at week $0(p<0.05, \mathrm{n}=4)$.

\subsection{Histological evaluation}

Histological evaluation of chondrocytes encapsulated in IPN gels after a 6-week culture period indicated higher matrix synthesis as compared to week 1 (Fig. 14). At week 1, safranin-O staining for GAGs was observed in a pericellular region of cells distributed uniformly in the IPN control group with no bioactive signals (Fig. 14A) as well as in IPNagg 4 (Fig. 14B) gel sections, while intense staining at the edge of IPN-agg 100 (Fig. 14C) and IPN-RGD 100 (Fig. 14D) was observed, which indicated that chondrocytes started migrating toward the edge of the gel (outgrowth). Staining intensity increased over time throughout the gel sections. At week 6, stronger Safranin-O staining was seen in the pericellular region as well as in the interterritorial region of the control IPN (Fig. 14E) and the IPN-agg 4 (Fig. 14F) gels. More accumulation of cell secreted proteoglycans at the edge in IPN-agg 100 (Fig. 14G) and IPN-RGD 100 (Fig. 14H) gels was clear evidence of outgrowth of encapsulated chondrocytes, unlike the IPN (Fig. 14E) and IPN-agg 4 gel (Fig. $14 \mathrm{~F}$ ) sections at week 6 . Cellular outgrowth was visible even after 1 week (images not shown) of culture and with further culturing until week 6 , an abundant matrix growth was generated at the edge, forming a continuous scaffold-free phase covering the entire outer surface of the gel constructs as seen in the inset pictures (Figs. 14G and 14H). Chondrocytes located adjacent to the edge of the gel containing aggrecan and RGD continuously formed small cell aggregates and expanded toward the gel surface, ultimately growing out to form the thick continuous layer on the interface as seen in Figs. 7C and 7D. 


\section{Discussion}

In our previous report, we investigated agarose-poly(ethylene glycol)-based IPN hydrogels that exhibited cytocompatibility and improved mechanical properties relative to their component networks [60]. The incorporation of peptide and aggrecan molecules in IPN scaffolds plays an important role in controlling cell adhesion and motility behaviors, and mechanical properties of tissue-engineered constructs. In the current study, our design principle of double network IPN hydrogel scaffolds is that the preconstruction of a bioactive PEGDA macromer with a RGD peptide attachment within one of the networks will lead to improved long-term cell viability and biosynthesis.

The higher swelling degree with the IPN with the higher concentration of aggrecan can be attributed to the presence of largely dispersed and negatively charged chondroitin sulfate (CS) and keratan sulfate chains associated with aggrecan in the IPN. The high osmotic pressure of the counter ions associated with negatively charged groups may be responsible for the increased swelling of the IPNs containing aggrecan relative to the other formulations. On the other hand, the RGD incorporation into the IPN hydrogels did not cause significant changes in the swelling properties of IPN hydrogel (Table 1). However, these swelling degrees decreased drastically at week 6 . This decrease in swelling properties can be associated with the hydrolytic degradation of peptide linkages and leaching of physically entrapped aggrecan molecules into surrounding media or consumption of aggrecan by cells. These results indicate that it was possible to control the swelling properties of IPN gels by tailoring the composition of the incorporated biomolecules and their concentration.

The inability of PEG hydrogels to perform cell-specific adhesion is a key limitation in tissue engineering. To make bulk cell-adhesive hydrogels, PEGDA can be copolymerized with monoacrylates of cell adhesive peptides. By functionalizing the N-terminal amines of RGD peptides with an Nhydroxyl succinimide (NHS) ester of acryloyl-PEG-NHS to produce RGD-PEG monoacrylate (RGD-PEGMA), monoacrylated RGD with or without PEG spacers can be synthesized [50,51, 66]. As a result, cell-adhesive hydrogels can be made by the copolymerization of RGD-PEGMA monomers with PEGDA upon photopolymerization. Having a PEG spacer, PEGDA hydrogels with RGD-MA can spread the cells specifically. Several cell lines such as chondrocytes, vascular endothelial cells (ECs), osteoblasts, neural cells, and marrow stromal cells (MSCs), and fibroblasts have been observed to immobilize on bioactive PEG hydrogels [37, 51, 66-68]. ACRL-PEG-RGD can copolymerize with PEGDA to create a cell-adhesive PEG second network in the IPN gels, but the distribution of RGD peptides in IPN hydrogels is assumed to be random because the RGD moiety is not expected to significantly affect the reactivity of the acrylate group and the extent of peptide incorporation in hydrogels is limited due to the monoacrylation of peptide, which affects hydrogel formation and its mechanical properties [50]. Higher compressive modulus and toughness compared to IPN gels in IPN-agg 100 and IPN-RGD 100 gels can be associated with the presence of negatively charged groups and their mutual repulsion that keep polymer chains apart and results in higher stiffness. Agarose has been shown to degrade hydrolytically in cell culture [69] and studies have outlined methods to create biodegradable PEG networks as well [70,71]. The significant decrease in shear modulus and toughness of cellular and acellular IPN-agg 100 and IPN-RGD 100 gels at week 6 could have been due to the hydrolytic degradation of peptide linkages and leaching of physically entrapped aggrecan molecules in the culture media, respectively. Therefore, these aggrecan incorporated and RGD immobilized agarose-PEG IPN implants can likely be optimized for in vivo degradation.

The aggregation and cell outgrowth phenomenon was similar to those observed by Verghese et al. [72], with bone marrow-derived mesenchymal stem cells (MSCs) encapsulated in the 
CS-based single network gel and recently by Gong et al. [73], with chondrocytes encapsulated in single network hydrogel systems. Gong et al. called this phenomenon "Edge Flourish". Of particular interest, and an unexpected result, was the heterogeneous distribution of cells observed at week 3 and especially at week 6 in the RGD and high aggrecan concentration groups. One possible explanation may be a heterogeneous distribution of the respective biomolecule prior to gelation due to interactions with cells, as both were incorporated in the agarose together with cells as a first step. In the case of aggrecan, its distribution is likely set after agarose gelation, but during the brief period where cells and aggrecan were present together prior to agarose gelation, cells may have preferentially bound and moved aggrecan molecules. Similarly, cells may have bound RGD and pulled RGD peptides into a heterogeneous distribution, which would have essentially been fixed after being covalently linked at the photopolymerization stage for the PEGDA network. Whatever the case, clearly the end result was a heterogeneous cell distribution, which points to preferential cell migration and/or cell proliferation. Given the extensive "Edge Flourish" observed with these two groups, cell migration is a highly likely explanation, with further contribution to heterogeneity from resulting cell proliferation. It is particularly noteworthy that the extensive accumulation of cells and matrix around the periphery of the IPN may have extremely important implications in vivo with regard to integration with surrounding cartilage, which is currently a major concern in cartilage regeneration efforts.

Our previous study with aggrecan under identical culture conditions at $40 \mu \mathrm{g} / \mathrm{mL}$ demonstrated significant improvements in cell viability and performance [33], and the results of the current study with the higher concentration of $100 \mu \mathrm{g} / \mathrm{mL}$ were highly consistent with our previous work in terms of percent viability as well as collagen and GAG production. The advantage for this comparison to our previous work is that it provides context for the results observed with RGD. Clearly, a new finding emerging from the current study was that the concentration of aggrecan plays a very important role, with significant effects seen previously with $40 \mu \mathrm{g} / \mathrm{mL}$ and even more so currently with $100 \mu \mathrm{g} / \mathrm{mL}$, standing in contrast to the limited effect seen currently with $4 \mu \mathrm{g} / \mathrm{mL}$. Therefore, future studies with comparable materials or conditions would likely benefit from an aggrecan concentration of over $40 \mu \mathrm{g} / \mathrm{mL}$

Designing a proper scaffold, which could provide the necessary mechanical stability and biological environment to the encapsulated cells, is a pivotal issue in cartilage engineering. A wide variety of biomaterials, including synthetic and naturally derived polymers, have been applied to cartilage tissue engineering. To this end, 3D bioactive IPN hydrogels have been identified as promising materials for encapsulating chondrocytes with the potential to yield functional cartilage tissues. We also outlined a method for peptide and aggrecan incorporation into otherwise poorly adhesive agarose-PEG IPN hydrogels to permit engineered bio-specific cell adhesion to these materials. A finding of this study has yielded an IPN gel with a notable combination of high mechanical strength, cyto-compatibility, and the ability to provide a suitable microenvironment for encapsulated cells to grow, proliferate, and produce cartilaginous tissue. We demonstrated here that the incorporation of host tissue-mimetic biomolecules such as covalently linked RGD peptide sequences or physically entrapped aggrecan within the IPN maintained long-term cell survivability and produced significantly more GAG-rich as well as collagen-rich tissues. Given the comparable performance of cells in an RGD or high concentration aggrecan environment, RGD is recommended over aggrecan due to the lower cost, although manufacturing does involve a more complex incorporation of RGD due to the involved chemistry rather than simply incorporating aggrecan within the agarose, and aggrecan may be a valuable chondroinductive signal for mesenchymal stem cells [34], which is of significant translational relevance. 


\section{Conclusions}

In the current study, we successfully designed and synthesized $R G D$-functionalized and aggrecan-incorporated engineered agarose-PEGDA IPN hydrogel materials, resulting in IPNs with a greater compressive modulus, higher long-term cell viability (more than 70\%), and improved GAG and collagen synthesis. However, any improvement with aggrecan and RGD in vitro relative to control IPN scaffolds would need to be significant and substantial to justify the additional regulatory scrutiny and cost, particularly with aggrecan. With comparable performance between RGD and the high aggrecan concentration, the RGD would be preferred for use considering a lower cost and possible variable aggrecan purity. However, the aggrecan may be more beneficial in future studies with chondroinduction of stem cells, and considering its ease of incorporation (simple physical mixing instead of chemical reaction), aggrecan may prove to be a better choice than RGD in future applications.

\section{Acknowledgments}

This work was supported by the National Institutes of Health (R21 EB008783) and the National Science Foundation (DMR 0805264). We gratefully thank Dr. David Moore and Heather Shinogle of the University of Kansas Microscopy and Analytical Imaging Laboratory for their assistance with 3D confocal fluorescence microscopic techniques and SEM imaging. We are also grateful to Sarah Neuenswander and Justin Douglas for their assistance in ${ }^{1} \mathrm{H}$ NMR spectroscopy analysis. Access to the PerkinElmer ATR-FTIR instrument was provided by Dr. Paulette Spencer, director of the Bioengineering Research Center (BERC) of the University of Kansas. We gratefully acknowledge this access and the assistance provided by Dr. Charles Ye for training on FTIR.

\section{References}

1. Langer R, Vacanti JP. Tissue engineering. Science. 1993; 260:920-6. [PubMed: 8493529]

2. Peppas NA, Hilt JZ, Khademhosseini A, Langer R. Hydrogels in biology and medicine: From molecular principles to bionanotechnology. Adv mater. 2006; 18:1345-60.

3. Cushing MC, Anseth KS. Materials science. Hydrogel cell cultures. Science. 2007; 316:1133-4.

4. Lee KY, Mooney DJ. Hydrogels for tissue engineering. Chem Rev. 2001; 101:1869-79. [PubMed: 11710233]

5. Kretlow JD, Klouda L, Mikos AG. Injectable matrices and scaffolds for drug delivery in tissue engineering. Adv Drug Deliv Rev. 2007; 59:263-73. [PubMed: 17507111]

6. Chung C, Burdick JA. Engineering cartilage tissue. Adv Drug Deliv Rev. 2008; 60:243-62. [PubMed: 17976858]

7. Haines LA, Rajagopal K, Ozbas B, Salick DA, Pochan DJ, Schneider JP. Light-activated hydrogbel formation via the triggered folding and self-assembly of a designed peptide. J Am Chem Soc. 2005; 127:17025-9. [PubMed: 16316249]

8. Elisseeff J, Anseth K, Sims D, McIntosh W, Randolph M, Langer R. Transdermal photopolymerization for minimally invasive implantation. Proc Natl Acad Sci U S A. 1999; 96:3104-7. [PubMed: 10077644]

9. Buxton AN, Zhu J, Marchant R, West JL, Yoo JU, Johnstone B. Design and characterization of poly(ethylene glycol) photopolymerizable semi-interpenetrating networks for chondrogenesis of human mesenchymal stem cells. Tissue Eng. 2007; 13:2549-60. [PubMed: 17655489]

10. Griffith LG, Swartz M. Capturing complex 3D tissue physiology in vitro. Nat Rev Mol Cell Biol. 2006; 7:211. [PubMed: 16496023]

11. Calvert P. Hydrogels for soft machines. Adv Mater. 2009; 21:743-56.

12. Vendamme R, Onoue SY, Nakao A, Kunitake T. Robust free-standing nanomembranes of organic/ inorganic interpenetrating networks. Nat Mater. 2006; 5:494-501. [PubMed: 16715083]

13. Lee W, Chen YJ. Studies on preparation and swelling properties of the N-isopropylacrylamidechitosan semi IPN and IPN hydrogels. J Appl Polym Sci. 2001; 82:2487-96. 
14. Weng L, Gouldstone A, Wu Y, Chen W. Mechanically strong double network photocrosslinked hydrogels from N,N-dimethylacrylamide and glycidyl methacrylated hyaluronan. Biomaterials. 2008; 29:2153-63. [PubMed: 18272215]

15. Suekama TC, Hu J, Kurokawa T, Gong JP, Gehrke SH. Double-network strategy improves fracture properties of chondroitin sulfate networks. Acs Macro Lett. 2013; 2:137-40.

16. Gong JP, Katsuyama Y, Kurokawa T, Osada Y. Double-network hydrogels with extremely high mechanical strength. Adv Mater. 2003; 15:1155.

17. Huang M, Furukawa H, Tanaka Y, Nakajima T, Osada Y, Gong JP. Importance of entanglement between first and second components in high-strength double network gels. Macromolecules. 2007; 40:6658.

18. Kaneko D, Tada T, Kurokawa T, Gong JP, Osada Y. Mechanically strong hydrogels with ultra-low frictional coefficients. Adv Mater. 2005; 17:535.

19. Kwon H, Osada Y, Gong J. Polyelectrolyte gels-fundamentals and applications. Polymer Journal. 2006; 38:1211-9.

20. Na Y, Kurokawa T, Katsuyama Y, Tsukeshiba H, Gong JP, Osada Y, et al. Structural characteristics of double network gels with extremely high mechanical strength. Macromolecules. 2004; 37:5370.

21. Nakayama A, Kakugo A, Gong JP, Osada Y, Takai M, Erata T, et al. High mechanical strength double-network hydrogel with bacterial cellulose. Adv Funct Mater. 2004; 14:1124-8.

22. Tanaka Y, Kuwabara R, Na YH, Kurokawa T, Gong JP, Osada Y. Determination of fracture energy of high strength double network hydrogels. J Phys Chem B. 2005; 109:11559-62. [PubMed: 16852418]

23. Tsukeshiba H, Huang M, Na YH, Kurokawa T, Kuwabara R, Tanaka Y, et al. Effect of polymer entanglement on the toughening of double network hydrogels. J Phys Chem B. 2005; 109:163049. [PubMed: 16853073]

24. Yasuda K, Ping Gong J, Katsuyama Y, Nakayama A, Tanabe Y, Kondo E, et al. Biomechanical properties of high-toughness double network hydrogels. Biomaterials. 2005; 26:4468-75. [PubMed: 15701376]

25. Hauqe A, Kurokawa T, Gong JP. Super tough double network hydrogels and their application as biomaterials. Polymer. 2012; 53:1805-22.

26. Sun JY, Zhao X, Illeperuma WR, Chaudhuri O, Oh KH, Mooney DJ, et al. Highly stretchable and tough hydrogels. Nature. 2012; 489:133-6. [PubMed: 22955625]

27. Darnell MC, Sun JY, Mehta M, Johnson C, Arany PR, Suo Z, et al. Performance and biocompatibility of extremely tough alginate/polyacrylamide hydrogels. Biomaterials. 2013; 34:8042-8. [PubMed: 23896005]

28. Dee KC, Anderson TT, Bizios R. Osteoblast population migration characteristics on substrates modified with immobilized adhesive peptides. Biomaterials. 1999; 20:221-7. [PubMed: 10030598]

29. Rezania A, Healy K. Biomimetic peptide surfaces that regulate adhesion, spreading, cytoskeletal organization, and mineralization of the matrix deposited by osteoblast-like cells. Biotechnol Prog. 1999; 15:19-32. [PubMed: 9933510]

30. Maroudas, A. Physicochemical properties of articular cartilage. In: Freeman, MAR., editor. Adult Articular Cartilage. Pitman Medical; Kent, UK: 1979. p. 215-90.

31. Deng Y, Hu JC, Athanasiou KA. Isolation and chondroinduction of a dermis-isolated, aggrecansensitive subpopulation with high chondrogenic potential. Arthritis Rheum. 2007; 56:168-76. [PubMed: 17195219]

32. French MM, Rose S, Canseco J, Athanasiou KA. Chondrogenic differentiation of adult dermal fibroblasts. Ann Biomed Eng. 2004; 32:50-6. [PubMed: 14964721]

33. Ingavle GC, Frei AW, Gehrke SH, Detamore MS. Incorporation of aggrecan in interpenetrating network hydrogels to improve cellular performance for cartilage tissue engineering. Tissue Eng Part A. 2013; 19:1349-59. [PubMed: 23379843]

34. Renth AN, Detamore MS. Leveraging "raw materials" as building blocks and bioactive signals in regenerative medicine. Tissue Eng Part B-Reviews. 2012; 18:341-62. 
35. Benoit DS, Anseth KS. The effect on osteoblast function of colocalized RGD and PHSRN epitopes on PEG surfaces. Biomaterials. 2005; 26:5209-20. [PubMed: 15792548]

36. Benoit DS, Tripodi MC, Blanchette JO, Langer SJ, Leinwand LA, Anseth KS. Integrin-linked kinase production prevents anoikis in human mesenchymal stem cells. J Biomed Mater Res A. 2007; 81:259-68. [PubMed: 17335036]

37. Burdick JA, Anseth KS. Photoencapsulation of osteoblasts in injectable RGD-modified PEG hydrogels for bone tissue engineering. Biomaterials. 2002; 23:4315-23. [PubMed: 12219821]

38. Hwang NS, Varghese S, Theprungsirikul P, Canver A, Elisseeff J. Enhanced chondrogenic differentiation of murine embryonic stem cells in hydrogels with glucosamine. Biomaterials. 2006; 27:6015-23. [PubMed: 16872674]

39. Nuttelman CR, Tripodi MC, Anseth KS. Synthetic hydrogel niches that promote hMSC viability. Matrix Biol. 2005; 24:208-18. [PubMed: 15896949]

40. Shu XZ, Ghosh K, Liu Y, Palumbo FS, Luo Y, Clark RA, et al. Attachment and spreading of fibroblasts on an RGD peptide-modified injectable hyaluronan hydrogel. J Biomed Mater Res A. 2004; 68:365-75. [PubMed: 14704979]

41. Weber LM, Hayda KN, Haskins K, Anseth KS. The effects of cell-matrix interactions on encapsulated beta-cell function within hydrogels functionalized with matrix-derived adhesive peptides. Biomaterials. 2007; 28:3004-11. [PubMed: 17391752]

42. West J, Hubbell J. Atala A. Bioactive polymers. Synthetic biodegradable polymer scaffolds. Boston Birkhauser. 1997:83-95. MD.

43. Lutolf MP, Hubbell JA. Synthetic biomaterials as instructive extracellular microenvironments for morphogenesis in tissue engineering. Nat Biotechnol. 2005; 23:47-55. [PubMed: 15637621]

44. Griffith LG, Naughton G. Tissue engineering-current challenges and expanding opportunities. Science. 2002; 295:1009-14. [PubMed: 11834815]

45. Hirano Y, Mooney D. Peptide and protein presenting materials for tissue engineering. AdV Mater. 2004; 16:17-25.

46. Ito Y. Covalently immobilized biosignal molecule materials for tissue engineering. Soft Matter. 2008; 4:46-56.

47. Schaffner P, Dard MM. Structure and function of RGD peptides involved in bone biology. Cell Mol Life Sci. 2003; 60:119-32. [PubMed: 12613662]

48. Hersel U, Dahmen C, Kessler H. RGD modified polymers: biomaterials for stimulated cell adhesion and beyond. Biomaterials. 2003; 24:4385-415. [PubMed: 12922151]

49. Kantlehner M, Finsinger D, Meyer J, Schaffner P, Jonczyk A, Diefenbach B, et al. Selective RGDmediated adhesion of osteoblasts at surfaces of implants. Angew Chem, Int Ed. 1999; 38:560-2.

50. Hern D, Hubbell J. Incorporation of dhesion peptides into nonadhesive hydrogels useful for tissue engineering. J Biomed Mater Res. 1998; 39:266-76. [PubMed: 9457557]

51. Yang F, Williams CG, Wang DA, Lee H, Manson PN, Elisseeff J. The effect of incorporating RGD adhesive peptide in polyethylene glycol diacrylate hydrogel on osteogenesis of bone marrow stromal cells. Biomaterials. 2005; 26:5991-8. [PubMed: 15878198]

52. West J, Hubbell J. Polymeric biomaterials with degradation sites for proteases involved in cell migration. Macromolecules. 1999; 32:241-4.

53. Mann B, Gobin A, Tsai A, Schmedlen R, West J. Smooth muscle cell growth in photopolymerized hydrogel with cell adhesive and proteolytically degradable domains: Synthetic ECM analogs for tissue engineering. Biomaterials. 2001; 22:3045-51. [PubMed: 11575479]

54. Mann B, West J. Cell adhesion peptides alter smooth muscle cell adhesion, proliferation, migration, and matrix protein synthesis on modified surfaces and in polymer scaffolds. J Biomed Mater Res. 2002; 60:86-93. [PubMed: 11835163]

55. Gobin A, West J. Val-ala-pro-gly, an elastin derived nonintegrin ligand: Smooth muscle cell adhesion and specificity. J Biomed Mater Res A. 2003; 67:255-9. [PubMed: 14517884]

56. Yoon J, Song S, Lee D, Park T. Immobilization of cell adhesive RGD peptide onto the surface of highly porous biodegradable scaffolds fabricated by a gas foaming/salt leaching method. Biomaterials. 2004; 25:5613-20. [PubMed: 15159077] 
57. Ingavle GC, Dormer NH, Gehrke SH, Detamore MS. Using chondroitin sulfate to improve the viability and biosynthesis of chondrocytes encapsulated in interpenetrating network (IPN) hydrogels of agarose and poly(ethylene glycol) diacrylate. J Mater Sci Mater Med. 2012; 23:15770. [PubMed: 22116661]

58. Wang L, Detamore MS. Effects of growth factors and glucosamine on porcine mandibular condylar cartilage cells and hyaline cartilage cells for tissue engineering applications. Arch Oral Biol. 2009; 54:1-5. [PubMed: 18640663]

59. Wang L, Lazebnik M, Detamore MS. Hyaline cartilage cells outperform mandibular condylar cartilage cells in a TMJ fibrocartilage tissue engineering application. Osteoarthritis Cartilage. 2009; 17:346-53. [PubMed: 18760638]

60. DeKosky BJ, Dormer NH, Ingavle GC, Roatch CH, Lomakin J, Detamore MS, et al. Hierarchically designed agarose and poly(ethylene glycol) interpenetrating network hydrogels for cartilage tissue engineering. Tissue Eng Part C Methods. 2010; 16:1533-42. [PubMed: 20626274]

61. Treloar, LRG. The physics of rubber elasticity. Oxford University Press; 2005.

62. Anderson TF. Techniques for the preservation of three-dimensional structure in preparing specimens for the electron microscope. Trans NY Acad Sci. 1951; 13:130-3.

63. Farndale RW, Buttle DJ, Barrett AJ. Improved quantitation and discrimination of sulphated glycosaminoglycans by use of dimethylmethylene blue. Biochim Biophys Acta. 1986; 883:173-7. [PubMed: 3091074]

64. Wang L, Tran I, Seshareddy K, Weiss ML, Detamore MS. A comparison of human bone marrowderived mesenchymal stem cells and human umbilical cord-derived mesenchymal stromal cells for cartilage tissue engineering. Tissue Eng Part A. 2009; 15:2259-66. [PubMed: 19260778]

65. Rennerfeldt DA, Renth AN, Talata Z, Gehrke SH, Detamore MS. Tuning mechanical performance of poly(ethylene glycol) and agarose interpenetrating network hydrogels for cartilage tissue engineering. Biomaterials. 2013; 34:8241-57. [PubMed: 23932504]

66. Hahn MS, Taite LJ, Moon JJ, Rowland MC, Ruffino KA, West JL. Photolithographic patterning of polyethylene glycol hydrogels. Biomaterials. 2006; 27:2519-24. [PubMed: 16375965]

67. Nuttelman CR, Rice MA, Rydholm AE, Salinas CN, Shah DN, Anseth KS. Macromolecular monomers for the synthesis of hydrogel niches and their application in cell encapsulation and tissue engineering. Prog Polym Sci. 2008; 33:167-79. [PubMed: 19461945]

68. Turturro MV, Sokic S, Larson JC, Papavasiliou G. Effective tuning of ligand incorporation and mechanical properties in visible light photopolymerized poly(ethylene glycol) diacrylate hydrogels dictates cell adhesion and proliferation. Biomed Mater. 2013; 8:025001. [PubMed: 23343533]

69. Rosa ED, Urciuolo F, Borselli C, Gerbasio D, Imparato G, Netti PA. Time and space evolution of transport properties in agarose-chondrocyte constructs. Tissue Eng. 2006; 12:2193. [PubMed: 16968160]

70. Rice MA, Anseth KS. Controlling cartilaginous matrix evolution in hydrogels with degradation triggered by exogenous addition of an enzyme. Tissue Eng. 2007; 13:683-91. [PubMed: 17266401]

71. Sawhney AS, Pathak CP, Hubbell JA. Bioerodible hydrogels based on photopolymerized poly (ethylene glycol)-co-poly (a-hydroxy acid) diacrylate macromers. Macromolecules. 1993; 26:581.

72. Varghese S, Hwang NS, Canver AC, Theprungsirikul P, Lin DW, Elisseeff J. Chondroitin sulfate based niches for chondrogenic differentiation of mesenchymal stem cells. Matrix Biol. 2008; 27:12-21. [PubMed: 17689060]

73. Gong Y, Su K, Lau TT, Zhou R, Wang DA. Microcavitary hydrogel-mediating phase transfer cell culture for cartilage tissue engineering. Tissue Eng Part A. 2010; 16:3611-22. [PubMed: 20666616] 


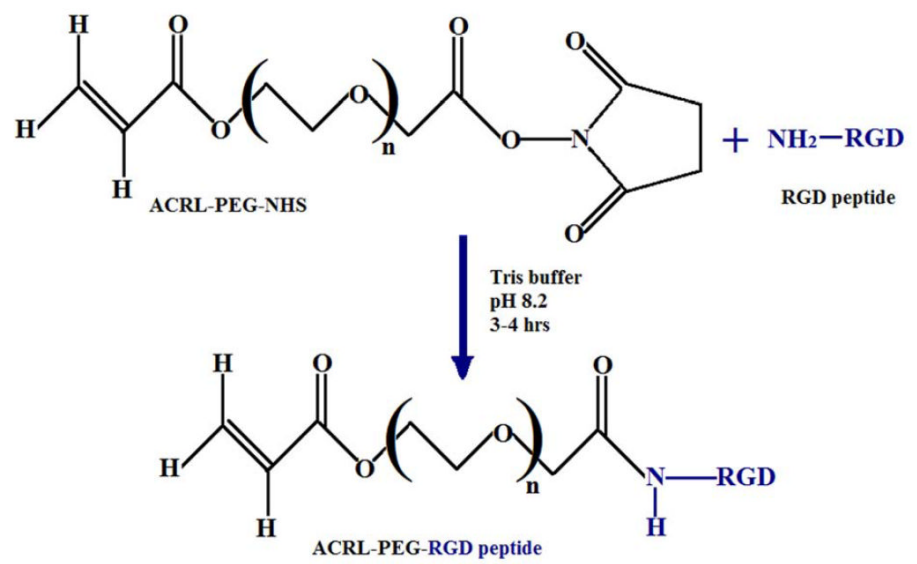

Fig. 1.

Reaction scheme showing synthesis of RGD-modified PEGDA (ACRL-PEG-RGD) biomacromer. 


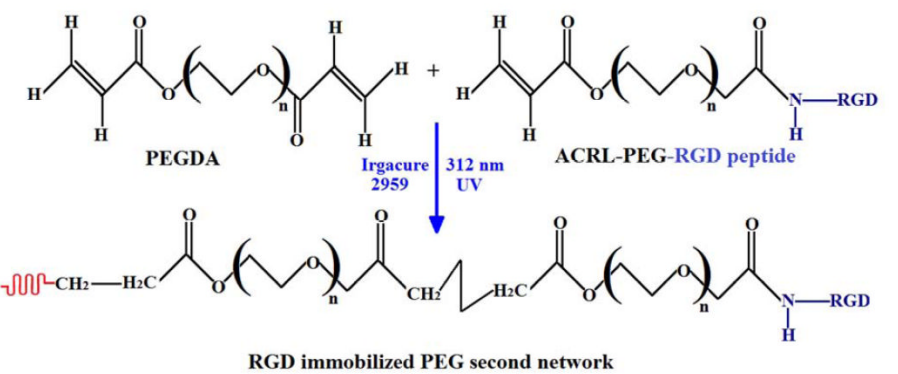

Fig. 2.

Reaction scheme showing formation of the PEG second network hydrogel containing the RGD peptide. 

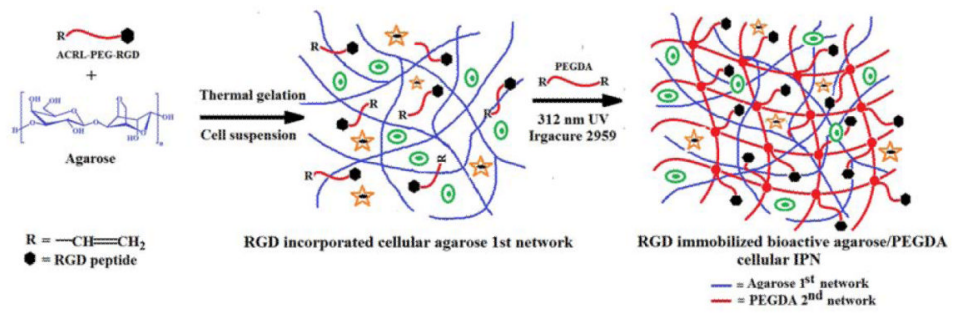

Fig. 3.

Schematic representation showing the formation of cellular agarose-PEGDA IPNs containing immobilized RGD peptide sequences on the PEGDA second network. 


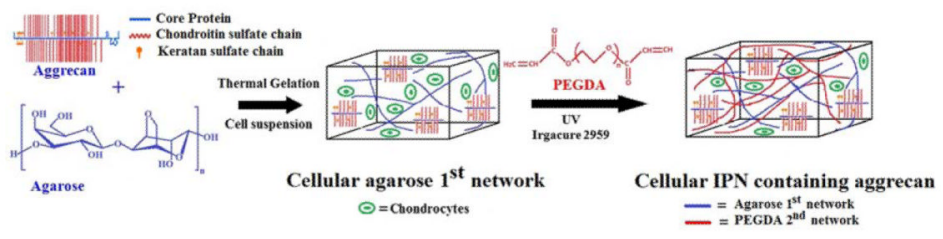

Fig. 4.

Schematic representation showing formation of cellular agarose-PEGDA IPN containing physically entrapped aggrecan as a bioactive signal. 


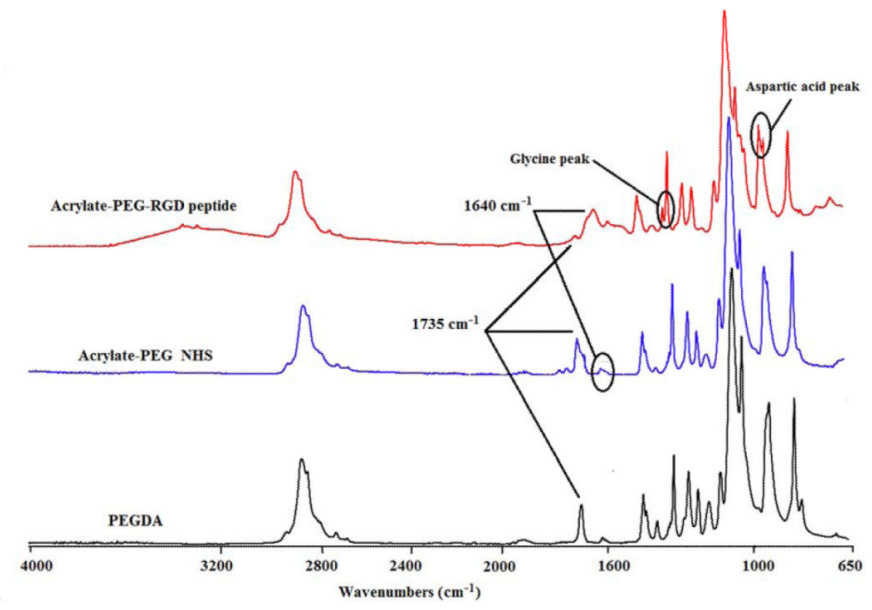

Fig. 5.

Attenuated total reflection-Fourier transform infrared (ATR-FTIR) spectra of ACRL-PEGNHS and ACRL-PEG-RGD peptide. Absorbance peaks at $1640 \mathrm{~cm}^{-1}(-\mathrm{C}=\mathrm{O}), 1343$ $\mathrm{cm}^{-1}$ (Glycine), and $964 \mathrm{~cm}^{-1}$ (aspartic acid) clearly indicated the conjugation of the RGD peptide on the PEGDA chain. 


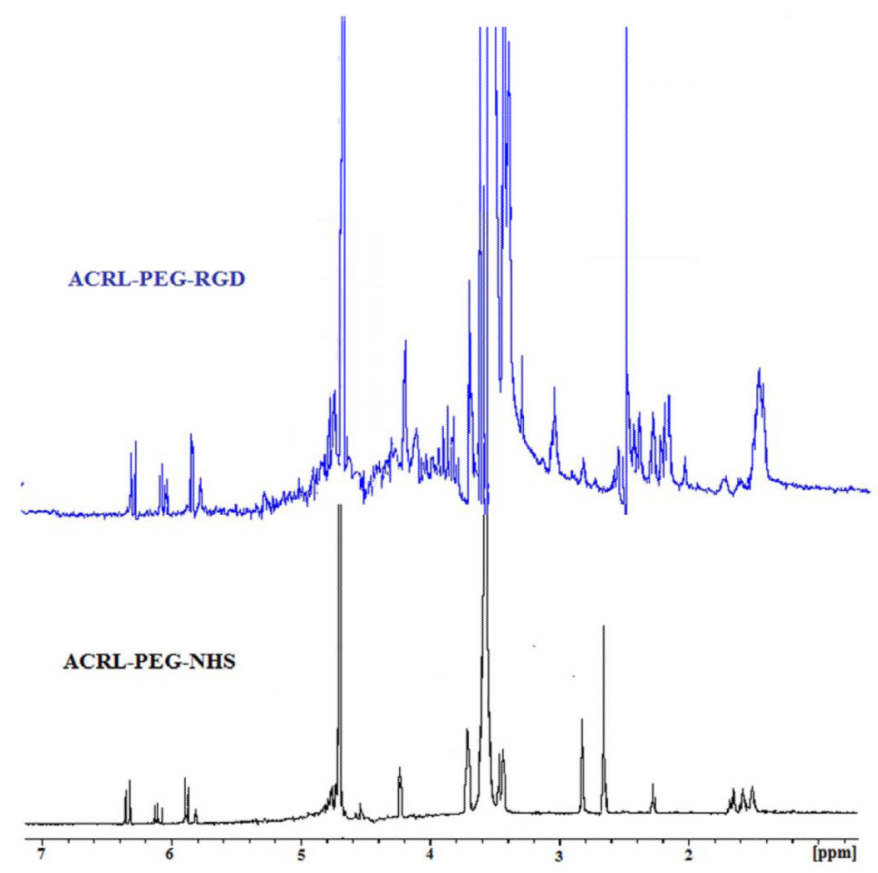

Fig. 6.

1H NMR spectra of ACRL-PEG-NHS and ACRL-PEG-RGD macromers. Appearance of characteristic proton peaks of peptides at 2.8 and $3.2 \mathrm{ppm}$ and the disappearance of proton peak of N-hydroxy succinimidyl ester at $2.9 \mathrm{ppm}$ confirm the peptide conjugation with acrylated PEGDA macromer. 

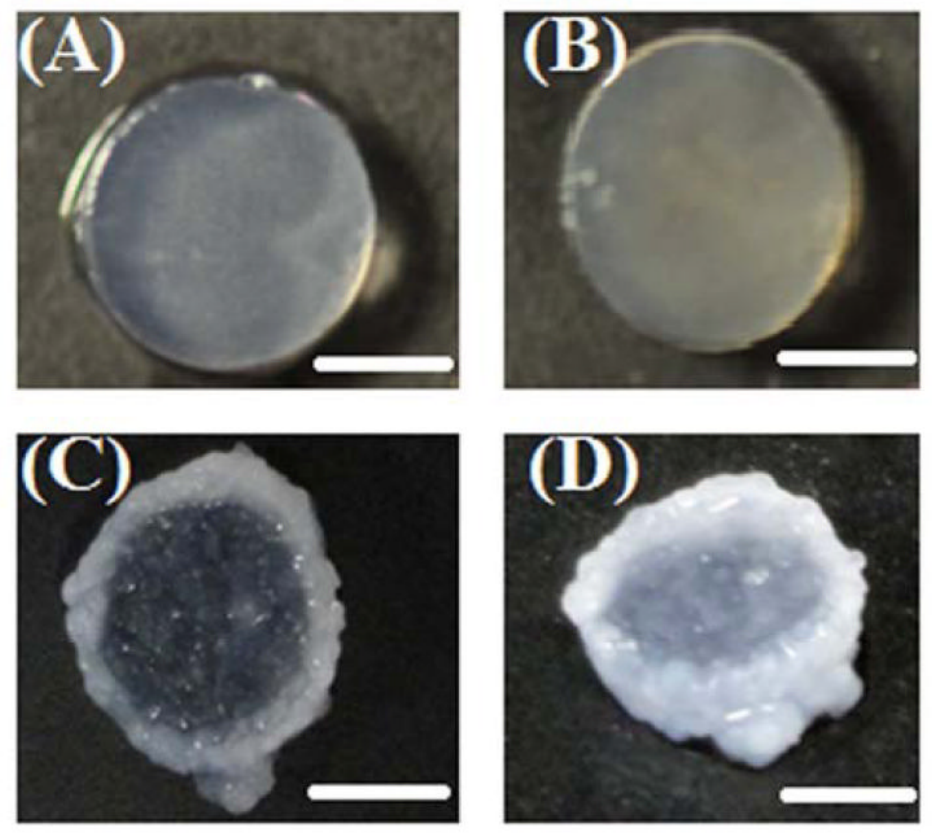

Fig. 7.

Representative macroscopic images of equilibrium swelled cellular IPN gels at week 6: (A) IPN gel with no bioactive molecules; (B) IPN gels containing $4 \mu \mathrm{g} / \mathrm{mL}$ aggrecan; (C) IPN gel containing $100 \mu \mathrm{g} / \mathrm{mL}$ aggrecan and (D) IPN gel containing $100 \mu \mathrm{g} / \mathrm{mL}$ RGD.

Chondrocyte outgrowth is visible at the edge in IPN gels containing high concentration of aggrecan as well as RGD immobilized IPN gels. Scale Bars $=3 \mathrm{~mm}$. 

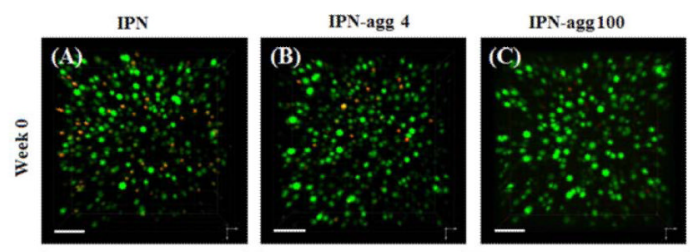

IPN-RGD 100
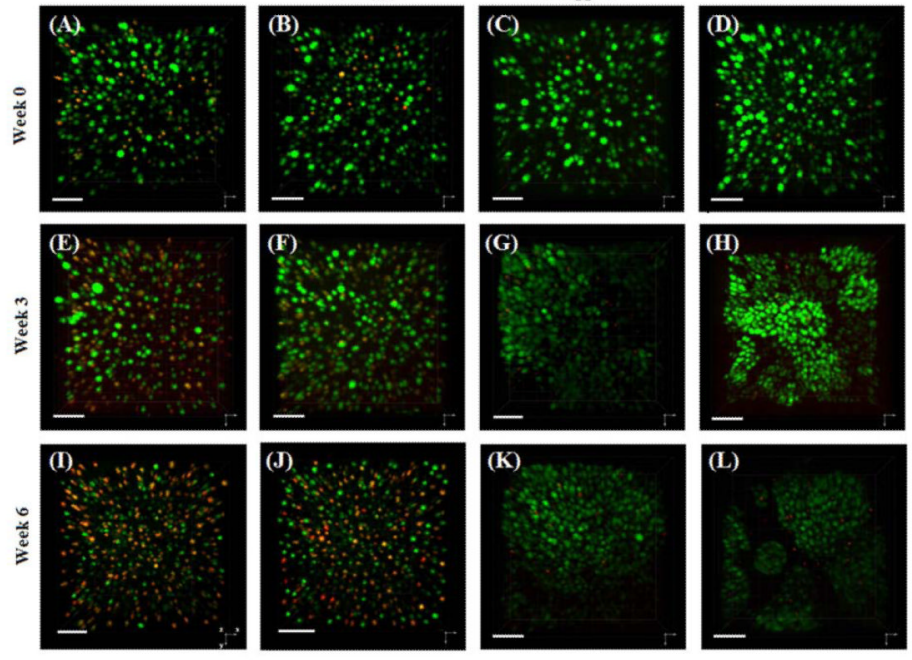

Fig. 8.

Spinning disc confocal microscope live/dead images of encapsulated chondrocytes in IPN network at week 0 (A-D) for IPN, IPN-agg 4, IPN-agg 100, and IPN-RGD 100, respectively, at week $3(\mathrm{E}-\mathrm{H})$ for IPN, IPN-agg 4, IPN-agg 100, and IPN-RGD 100, respectively, and at week 6 (I-L) for IPN, IPN-agg 4, IPN-agg 100, and IPN-RGD 100, respectively. Green (calcein AM) dye indicated viable (live) cell populations, while red (ethidium homodimer) dye indicated dead cells. Scale bar $=50 \mu \mathrm{m}$. 


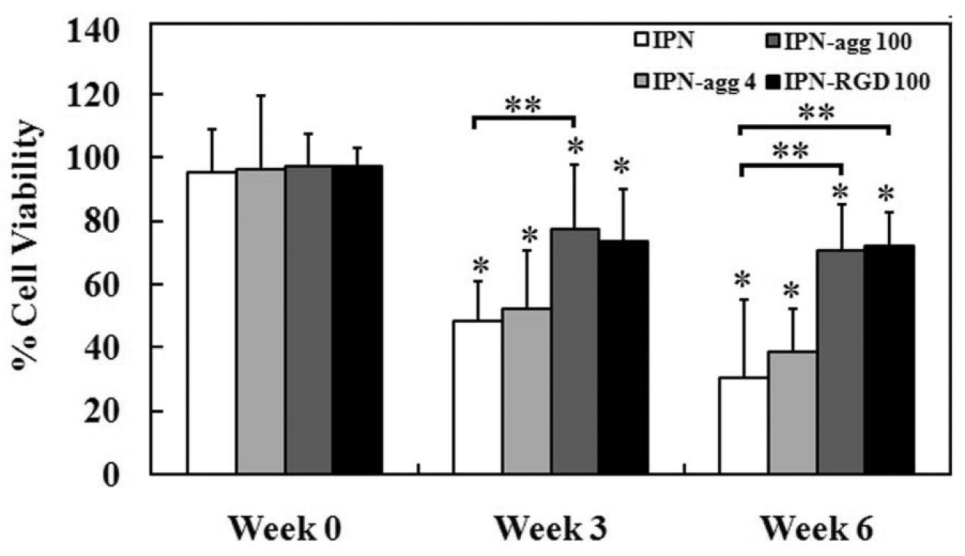

Fig. 9.

Percent cell viability of encapsulated chondrocytes by image analysis mask statistics. Multiple confocal Z-scan series were performed on a representative sample in each group (mean \pm standard deviation). * indicates statistically significant differences from week 0 ( $p$ $<0.05$ and $\mathrm{n}=3$ ), while $* *$ values indicates significant differences from the control group (IPN) at that time point $(p<0.05$ and $\mathrm{n}=3$ ). 

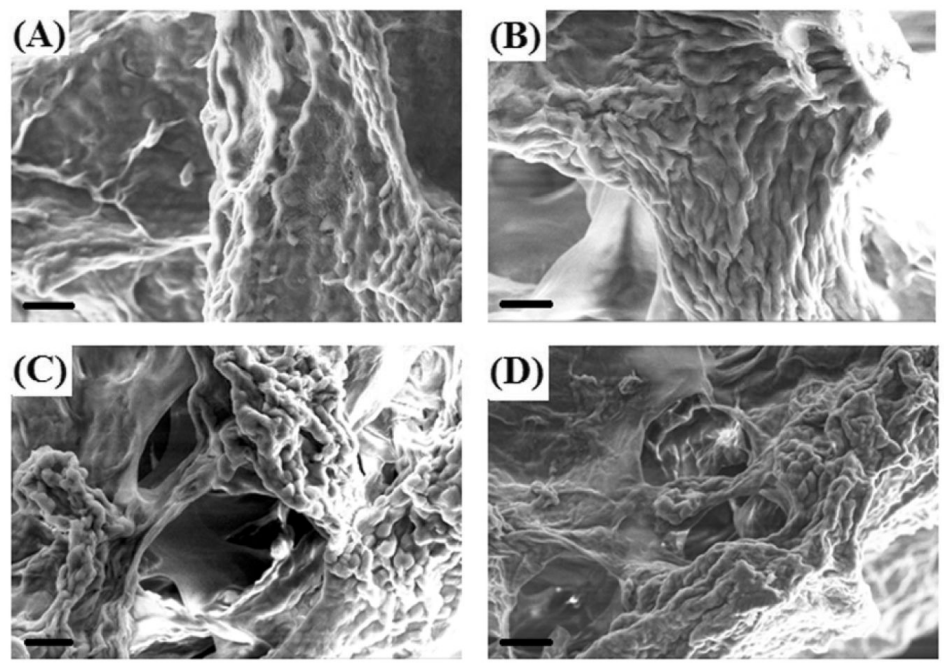

Fig. 10.

Scanning electron micrographs showing morphology of chondrocytes encapsulated in A) IPN with no bioactive signals, B) IPN-agg 4, C) IPN-agg 100, and D) IPN-RGD 100 at 6 weeks culture time. Scale Bar $=20 \mu \mathrm{m}$. 


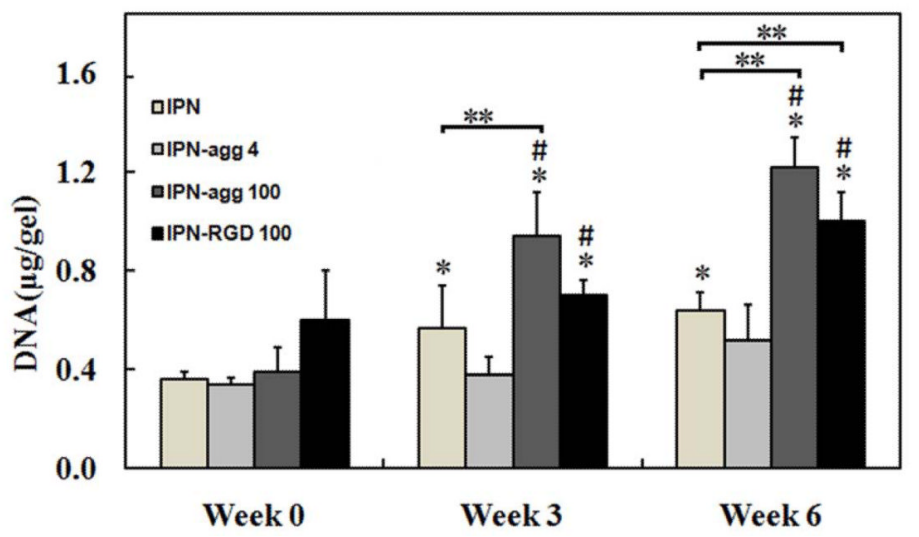

Fig. 11.

Total DNA content within IPN, IPN-agg 4, IPN-agg 100, and IPN-RGD 100 gels, respectively, at 0,3 , and 6 weeks. Error bars represent mean \pm standard deviation with $\mathrm{n}=4$. *indicates statistically significant differences in comparison with week 0 groups $(p<0.05)$, **values indicates significant differences from the control group (IPN) at that time point ( $p$ $<0.0)$ and \#indicates statistically significant differences in comparison with the other groups at that time point $(p<0.05)$. 

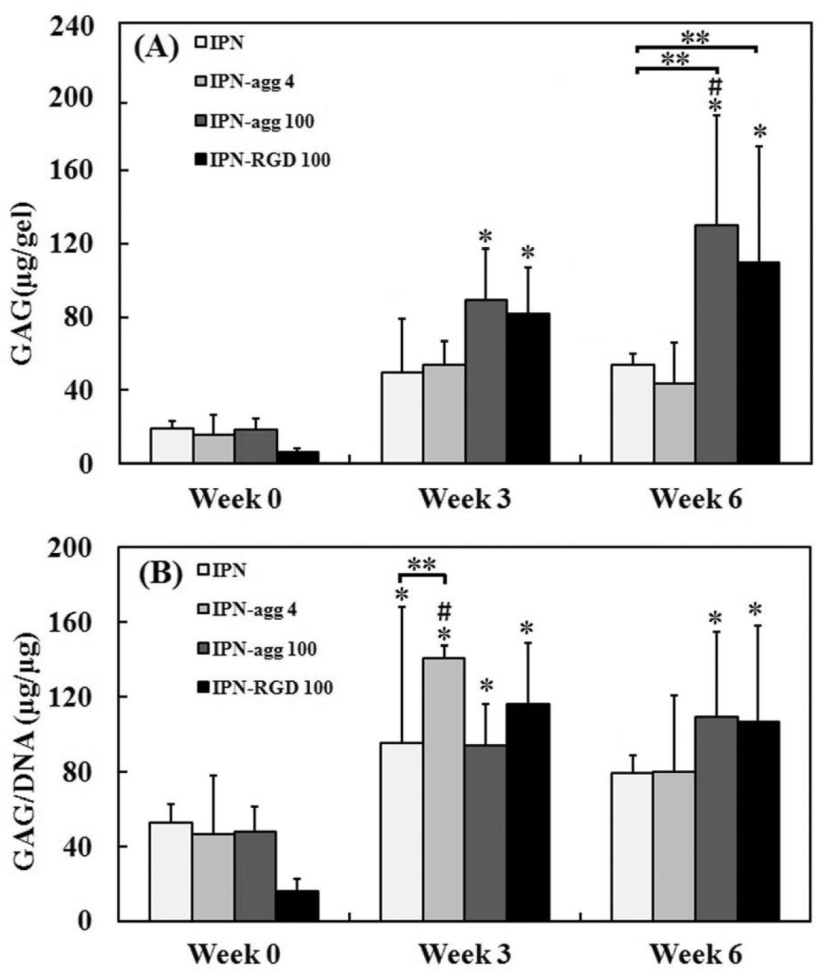

Fig. 12.

(A) Total sulfated GAG accumulated per IPN gel construct within each IPN, IPN-agg 4, IPN-agg 100, and IPN-RGD 100 constructs with encapsulated chondrocytes at 0, 3, and 6 weeks. (B) For each IPN gel group, the total GAG accumulated was normalized to DNA content (mean \pm deviation, $\mathrm{n}=4$ ). *indicates statistically significant differences in comparison with week 0 groups $(p<0.05)$, **values indicates significant differences from the control group (IPN) at that time point $(p<0.05)$ and \#indicates statistically significant differences in comparison with the other groups at that time point $(p<0.05)$. GAG $=$ glycosaminoglycan. Note that the GAG content associated with incorporated aggrecan was subtracted from the actual GAG value to provide the values reported here. 



Fig. 13.

Total hydroxyproline per IPN gel construct within each IPN, IPN-agg 4, IPN-agg 100, and IPN-RGD 100 constructs with encapsulated chondrocytes at 0, 3, and 6 weeks. (B) For each gel group, the total hydroxyproline content was normalized to DNA content (mean \pm deviation, $\mathrm{n}=4)$. Significance of the data at $p<0.05$. *indicates statistically significant differences in comparison to week 0 groups, $* *$ values indicates significant differences from the control group (IPN) at that time point $(p<0.05)$ and \#indicates statistically significant differences in comparison to the other groups at that time point. 

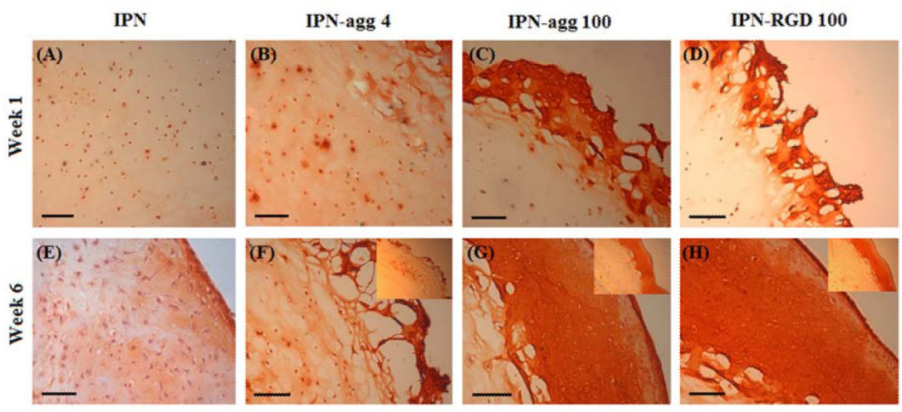

Fig. 14.

Safranin O staining of bioactive IPN gels encapsulated with chondrocytes at week 1 (A-D) for IPN, IPN-agg 4, IPN-agg 100, and IPN-RGD 100, respectively, and at week $6(\mathrm{E}-\mathrm{H})$ for IPN, IPN-agg 4, IPN-agg 100, and IPN-RGD 100, respectively. Inset pictures showing outgrowth of encapsulated chondrocytes at the edge of gels. (Scale bar $=100 \mu \mathrm{m})$. 
Table 1

Mechanical and swelling properties of acellular and cellular IPN gels

\begin{tabular}{|c|c|c|c|c|c|c|c|c|}
\hline \multirow[t]{2}{*}{ Gel type } & \multicolumn{2}{|c|}{$\begin{array}{l}\text { Compressive shear moduli } \\
\text { (G) }(\mathbf{k P a})^{a b c}\end{array}$} & \multicolumn{2}{|c|}{$\begin{array}{l}\text { Fracture Stress } \\
\qquad(\mathrm{MPa}) a b c\end{array}$} & \multicolumn{2}{|c|}{$\begin{array}{l}\text { Toughness } \\
\left(\mathbf{k J} / \mathbf{m}^{3}\right) a b c\end{array}$} & \multicolumn{2}{|c|}{$\begin{array}{l}\text { Swelling degree } \\
\mathrm{Q}^{c d e}\end{array}$} \\
\hline & Week 0 & Week 6 & Week 0 & Week 6 & Week 0 & Week 6 & Week 0 & Week 6 \\
\hline IPN & $39 \pm 8$ & $32 \pm 6$ & $0.8 \pm 0.2$ & $0.7 \pm 0.3$ & $127 \pm 35$ & $85 \pm 18$ & $10.2 \pm 2.2$ & $8.4 \pm 3.3$ \\
\hline IPN- agg 4 & $41 \pm 11$ & $27 \pm 6$ & $0.9 \pm 0.5$ & $0.6 \pm 0.2$ & $137 \pm 67$ & $78 \pm 27$ & $12.7 \pm 1.0$ & $9.7 \pm 4.1$ \\
\hline IPN-agg 100 & $48 \pm 13$ & $21 \pm 10$ & $1.0 \pm 0.7$ & $0.7 \pm 0.3$ & $149 \pm 34$ & $89 \pm 41$ & $24.5 \pm 5.7$ & $12.5 \pm 3.8$ \\
\hline IPN-RGD 100 & $42 \pm 10$ & $23 \pm 5$ & $1.2 \pm 0.6$ & $0.7 \pm 0.4$ & $132 \pm 40$ & $64 \pm 26$ & $15.5 \pm 0.9$ & $10.3 \pm 3.5$ \\
\hline IPN+ cell & $35 \pm 9$ & $22 \pm 7$ & $0.7 \pm 0.4$ & $0.4 \pm 0.3$ & $89 \pm 25$ & $72 \pm 19$ & - & - \\
\hline IPN-agg $4 \pm$ Cell & $37+11$ & $19 \pm 6$ & $0.8 \pm 0.4$ & $0.6 \pm 0.1$ & $92 \pm 31$ & $54 \pm 22$ & - & - \\
\hline IPN-agg $100 \pm$ Cell & $32 \pm 17$ & $30 \pm 15$ & $0.9 \pm 0.7$ & $0.8 \pm 0.2$ & $123 \pm 47$ & $82 \pm 23$ & - & - \\
\hline IPN-RGD $100 \pm$ Cell & $36 \pm 14$ & $21 \pm 7$ & $0.9 \pm 0.5$ & $0.7 \pm 0.3$ & $111 \pm 29$ & $56 \pm 20$ & - & - \\
\hline
\end{tabular}

All values are reported as mean \pm deviation, $\mathrm{n}=5$ for compression testing and 3 for swelling measurements

No swelling degree measurement were performed on cellular constructs due to limited sample numbers IPN = agarose-PEGDA interpenetrating network with no bioactive signals; IPN-agg 4 = agarose-PEGDA interpenetrating network with $4 \mu \mathrm{g} / \mathrm{mL}$ aggrecan; IPN-agg $100=$ agarose-PEGDA interpenetrating network with $100 \mu \mathrm{g} / \mathrm{mL}$ aggrecan and IPN-RGD $100=$ agarose-PEGDA interpenetrating network with $100 \mu \mathrm{g} / \mathrm{mL}$ RGD peptide

${ }^{a}$ - IPN-agg 100 and IPN-RGD 100 were statistically significant between week 0 and week $6(\mathrm{p}<0.05)$

${ }^{b}$ _ IPN-agg 100, IPN-agg 100 were statistically significant from IPN group, while no statistical significance among IPN, IPN-agg 4, IPN+ cell, IPN-agg 4+ cell, IPN-agg 100+cell and and IPN-RGD $100 \pm$ cell at week 0

${ }^{c}$ - No statistical significance among the groups at week 6

${ }^{d}$ - IPN-agg 100 and IPN-RGD 100 were statistically significant from IPN group at week $0(\mathrm{p}<0.05)$

$e^{e}$ IPN-agg 100 was statistically significant between week 0 and week $6(\mathrm{p}<0.05)$ 